\title{
Fifty Years of Prefrontal Cortex Research: Impact on Assessment
}

INS is approved by the American Psychological Association to sponso Continuing Education for psychologists INS maintains responsibility for this program and its content.

\author{
Paul W. Burgess, ${ }^{1}$ AND Donald T. Stuss $2,3,4$ \\ ${ }^{1}$ Institute of Cognitive Neuroscience, University College London \\ ${ }^{2}$ University of Toronto, Toronto, Ontario Canada \\ ${ }^{3}$ Sunnybrook Health Sciences Centre, Toronto, Ontario, Canada \\ ${ }^{4}$ Rotman Research Institute of Baycrest, Toronto, Ontario, Canada \\ (Received April 13, 2017; Final Revision June 19, 2017; Accepted June 22, 2017)
}

\begin{abstract}
Our knowledge of the functions of the prefrontal cortex, often called executive, supervisory, or control, has been transformed over the past 50 years. After operationally defining terms for clarification, we review the impact of advances in functional, structural, and theoretical levels of understanding upon neuropsychological assessment practice as a means of identifying 11 principles/challenges relating to assessment of executive function. Three of these were already known 50 years ago, and 8 have been confirmed or emerged since. Key themes over this period have been the emergence of the use of naturalistic tests to address issues of "ecological validity"; discovery of the complexity of the frontal lobe control system; invention of new tests for clinical use; development of key theoretical frameworks that address the issue of the role of prefrontal cortex systems in the organization of human cognition; the move toward considering brain systems rather than brain regions; the advent of functional neuroimaging, and its emerging integration into clinical practice. Despite these huge advances, however, practicing neuropsychologists are still desperately in need of new ways of measuring executive function. We discuss pathways by which this might happen, including decoupling the two levels of explanation (information processing; brain structure) and integrating very recent technological advances into the neuropsychologist's toolbox. (JINS, 2017, 23, 755-767)
\end{abstract}

Keywords: Prefrontal cortex, Frontal lobe, Executive function, Neuropsychological tests, Neuropsychology, Functional neuroimaging, Control function

\section{INTRODUCTION}

In 1928, Tilney proposed that the entire evolutionary existence of man could be considered as the age of the frontal lobes (Tilney, 1928). The research interest in this brain region was slow to evolve, however, but quickly escalated, particularly with the influential publications of Luria (e.g., 1966), interpreted for neuropsychological assessment by Christensen (1975). In 1986, Stuss and Benson summarized the known published literature in the English language (and some non-English) on the frontal lobes in a little over 300 pages. Comparison of two subsequent edited books (Stuss \& Knight, 2002, 2013) revealed that so much research had been done that by 2013 each of the sections could have themselves been books with a particular focus.

Covering all of such a rapid increase in our knowledge in one paper is clearly not possible. Our lens is one key aspect of

Correspondence and reprint requests to: Donald T. Stuss, Sunnybrook Health Sciences Centre, 2075 Bayview Ave. Toronto, ON M4N 3M5. E-mail: donaldt@stussassoc.ca the professional lives of neuropsychologists: assessment of "executive function." In particular, we focus on three major transition points that have affected the field significantly. They are not individual papers, but changes in direction or method. The first transition point arose from the development of tests specifically designed to assess particular executive symptoms; the second is related to the evolution of theory, and the relationship of theory development to new neuroanatomical knowledge; the third was the advent of imaging techniques that enabled an unprecedented window into the human brain and functioning. The impact of these transition points will be expressed in the form of 11 principles. Many of these principles actually represent challenges for the future.

The focus is on the functions traditionally associated with the prefrontal cortex (PFC), although the anatomical terms are sometimes also ambiguously used (i.e., frontal, prefrontal). There has been a rather unhelpful tendency in the field to use interchangeably the terms executive dysfunction and frontal lobe dysfunction. A related problem is that the term "executive" is defined in different ways, and often quite broadly. We elect to see executive functions in a narrower manner: a set of cognitive 
processes such as attentional control, planning, reasoning, problem solving, and monitoring. In this view, the terms are not synonymous. Executive functions then (see below) are one type of domain general processes. In this review, however, the term is used as originally expressed by a particular researcher. Regardless of one's bias, taking the perspective of the functions of the frontal lobes and differentiating it from executive functions provides a rationale for a methodological approach and a structure for operational definition.

\section{WHAT DID WE ALREADY KNOW 50 YEARS AGO?}

Some of the concepts that we currently hold in relation to frontal lobe function already existed in some form by the midto-late 1960s (Benton, 1991). The attempt to quantify the deficits was hampered by the golden age of mental testing with the pioneering work of figures such Cattell, Binet, Galton, and Spearman. This history of test development created two problems for the development of psychometric tests to measure the symptoms of frontal lobe dysfunction. First, the main concern of these early theorists was to measure intelligence. Yet it was apparent from the clinical studies of Phineas Gage and others (Harlow, 1848), and supported by animal research, that the main deficit these patients experienced was not a loss of some generalized "intelligence" resource. What did often occur with frontal damage was some alteration in character, which was hard to describe precisely, never mind quantify. Thus the object that was the focus of the psychometric theorists (measurement and identification of a construct called "intelligence) seemed tangential to the characterization of the symptoms of frontal lobe damaged patients.

A related problem was that the intelligence theorists emphasized the psychometric properties of their tests such as internal consistency and test-retest reliability. Yet if the frontal lobes support a system whose purpose it is to deal with novelty and adaptation of behavior, then then these metrics may be a poor indicator of the construct validity of the test (e.g., Burgess, 1997). Moreover, Stuss, Murphy, Binns, and Alexander (2003) demonstrated that inconsistency and variability may be a hallmark of frontal lobe dysfunction; a different psychometric approach is required. These problems lead to the first new principle that the last 50 years of research into frontal lobe function in humans has taught us:

New principle 1: You probably can't measure all cognitive abilities using the same methodological approach.

\section{Initial Assessment Efforts}

Despite these limitations, the first 50 years of the $20^{\text {th }}$ century were a rich period for the creation of mental tests, and several tests that we now think of as measures of "executive function" being created then. However, the link to frontal lobe function was usually not a principal aim, nor did notions of "executive function" exist then (the use of the term "executive" in relation to the frontal lobes is often attributed to Pribram, 1973).
One such example is the Verbal Fluency Test, part of Thurstone and Thurstone's (1938) attempts to discover the factorial structure of intelligence. Another is the Trail Making Test (TMT). Originally conceived as a measure of "distributed attention," considered as a component of general intelligence, this test was incorporated into the Army Individual Test Battery in 1944, and then later adapted for the Halstead-Reitan Neuropsychological Test Battery. It was Reitan (1958) who raised a further issue for the development of clinical tests of neuropsychological dysfunction. While his study demonstrated the utility of the TMT in distinguishing between patients with brain damage and those without, he also made the point that "patients with brain damage may perform poorly on the TMT as a consequence of several types of impairment associated with variously located brain lesions" (Reitan, 1958, p. 275). Here he highlights understanding of two principles that we have inherited:

Inherited principle 1: Tests of executive function often measure multiple cognitive abilities simultaneously.

Inherited principle 2: Tests of executive function do not just test frontal lobe function. They often may be failed by patients with dysfunction elsewhere as well.

We can add to this a further principle made clear in Reitan (1958): "this situation [i.e., that many different lesions cause many different impairments on executive tests] presents an advantage for the test in its use as a screening instrument but a possible disadvantage in terms of its potential use in differential lateralization or localization of brain lesions" (p. 275).

Inherited principle 3: The characteristics of the best clinical and the best experimental tests of executive function may differ since their aims differ.

These were the beginnings of theorizing about abilities for which the frontal lobes played a special supporting role (e.g., Halstead, 1947). Furthermore, notions that this might be worth considering independently from a construct of "intelligence" were already in gestation. Yet the faith in a specific link between damage to PFC and impairment on the tests appeared to be premature (e.g., Anderson, Bigler, \& Blatter, 1995). Reitan and Wolfson (1995) mused, after failing to find frontal specific deficits on the Category Test and Trails B, that "neuropsychologists should adopt a more critical attitude concerning so-called "frontal lobe deficits" (p. 50).

\section{THE MODERN PERSPECTIVE ON THE OLDER FINDINGS}

The past 50 years have seen the invention of several executive tests that were specifically designed for use with patients with frontal lobe involvement (e.g., Cognitive Estimation Task, Shallice and Evans, 1978; Tower of London test, Shallice, 1982; Homophone meaning generation test (Warrington, 2000), and the designs of these kinds of studies have been able to examine the relationship with constructs such as general intelligence. So, what have we learned about the three inherited principles over the past 50 years, and what have we added to them?

There is increasing evidence that tests designed to measure executive function often tap multiple cognitive abilities 


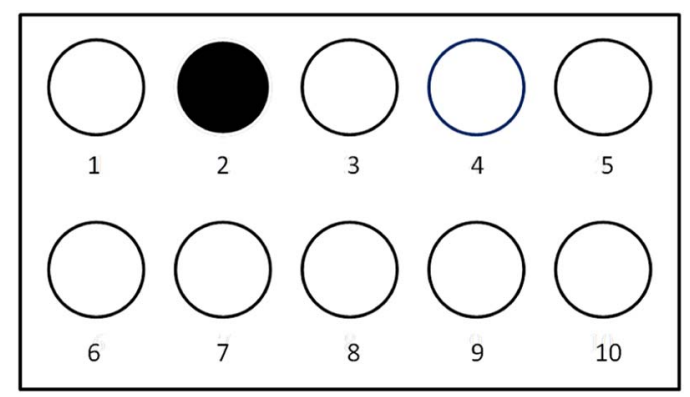

Fig. 1. A Brixton Test stimulus page. Participants are asked to predict the position of the filled circle on the next stimulus page (see text for description). Using this task, Burgess and Shallice (1996) showed that patients with frontal lobe lesions can show three different types of failure on this task, thus demonstrating that executive tasks may measure more than one construct simultaneously. Reverberi, Lavaroni, Giglib, and Skrapb (2005) later replicated the frontal deficit on a version of this test, and argued that the pattern of their results suggested functional dissociations between inductive reasoning, monitoring and working memory, with processes relevant to induction supported by left lateral frontal cortex and monitoring and checking by right lateral cortex.

simultaneously. Burgess and Shallice (1996a, 1997), for example, invented the Brixton Spatial Anticipation Test (Figure 1) to detect a tendency they had noticed in a few of their patients on executive tasks, bizarre answers that seemed unbounded by the task stimuli (called type 3 errors). Overall, patients with lesions outside the frontal lobes were not significantly poorer at this test than the healthy controls. Critically, the pattern of relationships between the errors and the background variables (e.g., WAIS IQ) showed that there seems to be two independent factors at work in performance of this test that are linked to location of lesion (total errors and percentage of type 3 errors were linked to one, and "moves away" from an attained rule were linked to another). This one test was capturing more than one symptom linked to frontal lobe dysfunction.

Indeed, the fact that many tests of executive functions (e.g., Wisconsin Card Sorting Test [WCST: Milner, 1963], TMT, Six Element Test, verbal fluency) tap potentially different frontal and nonfrontal functions and brain regions has been repetitively demonstrated (Table 1; see, e.g., Baddeley, Della Sala, Papagno, and Spinnler, 1997; Burgess et al., 1998, 2006; Shallice \& Burgess, 1991).

\section{EXECUTIVE TEST PERFORMANCE: BRAIN CIRCUITS VERSUS BRAIN REGIONS}

The second principle that was already known 50 years ago, confirmed and extended in the last 50 years, was that tests of executive function do not just test frontal lobe function. The evidence for an association between performance on executive tests and frontal lobe lesions is much more inconsistent than perhaps the early theorists appreciated. In a metaanalysis, Demakis (2004) found that participants with frontal damage performed significantly more poorly than patients with lesions outside the frontal lobes on all components of the
Stroop Test and Trails A. However, on two measures widely considered to be sensitive to frontal functions, namely the Category Test and Trails B, they were not significantly different. The conclusion: these "findings are surprising and not consistent with the long-held assumption that these latter measures are sensitive to frontal lobe damage" (p. 446).

Has research over the past 50 years explained why patients with lesions outside the prefrontal cortex fail executive tests, and why multiple regions within PFC can be implicated across different studies? We have identified one definite reason, although the precise details will take many decades to work out thoroughly. As structural neuroimaging and animal studies over the last few years have identified, prefrontal cortex (PFC) has a huge number of connections both within the PFC and outside it. These connections can be, for example, frontal-subcortical, frontal-limbic, frontal-cerebellar, and frontal-cortical. These connections in some cases are very distant from their origins. For instance, Catani et al. (2012) have shown how the frontal pole (i.e., the most anterior part of PFC) connects to the occipital lobes (i.e., the most posterior part of the brain) via long association and projection fibers referred to as the inferior fronto-occipital pathway and uncinate fasciculus. These kinds of connections are extremely extensive, and probably explain in large part the consistent associations in activation between certain subregions of the prefrontal cortex and other regions of the brain, as demonstrated for example by Gilbert, Gonen-Yaacovi, Benoit Bolle, \& Burgess (2010) (see Figure 2).

Gratton, Nomura, Perez, and D'Esposito (2012) using graph theory on resting state fMRI data demonstrated how focal brain damage could have a more widespread effect if the damage affects regions "important for the communication between networks." Regions such as the thalamus have also been considered to have connecting and integrating functions,
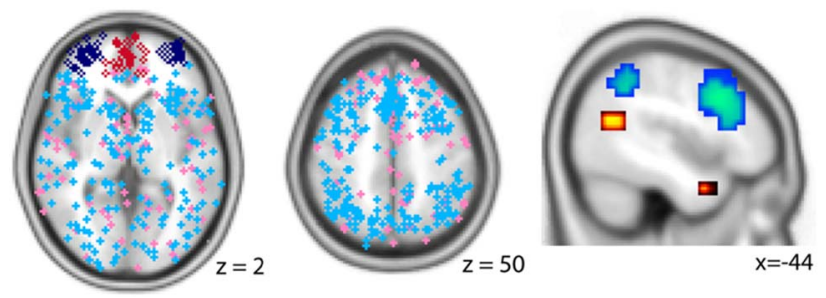

Fig. 2. Regions of the brain functionally coactive with area 10 of the prefrontal cortex (rostral PFC) as discovered by Gilbert et al. (2010). The left-hand picture shows the areas of medial area 10 identified in a meta-analysis shown in red, and the areas of lateral area 10 shown in dark blue. The pink and light blue points elsewhere show co-occurring foci of activation across 162 different studies. The middle panel shows the co-activations outside area 10 on a more dorsal slice of the brain. The right-hand picture shows example regions outside area 10 that were coactivated significantly more often than chance. Activation in lateral rostral PFC was particularly associated with co-activation in dorsal anterior cingulate, dorsolateral PFC, anterior insula and lateral parietal cortex. Medial rostral PFC was particularly associated with co-activation in posterior cingulate, posterior superior, temporal sulcus and the temporal pole. 
Table 1. Summary of Findings from Stuss and Colleagues' Studies of People with Frontal Lobe Lesions between 1998 and 2008

\begin{tabular}{|c|c|c|c|c|c|c|}
\hline Study & Condition & Variable & Right medial & Left medial & Right lateral & Left lateral \\
\hline \multirow[t]{3}{*}{ 1. Stuss et al. (1998) } & 1A. Letter fluency & Errors & & & & $9 / 46,46,44,45,47 / 12$ \\
\hline & 1B. Letter fluency & No. of words & $6 \mathrm{~A}, 8 \mathrm{~B}, 9,24$ & $6 \mathrm{~A}, 8 \mathrm{~B}, 9,24$ & & $9 / 46,46,44,45,47 / 12$ \\
\hline & 1C. Semantic fluency & No. of words & & & & $\begin{array}{c}9 / 46,46,44,45 \\
47 / 12,5,7,40\end{array}$ \\
\hline 2. Shammi \& Stuss (1999) & Humor judgment & Two variables & $8 \mathrm{~B}, 9,10 \mathrm{~s}$ & & $8 \mathrm{~B}, 9,10 \mathrm{~s}$ & \\
\hline \multirow[t]{10}{*}{ 3. Stuss et al. (2000) } & 3A. WCST 128 & Categories & $\begin{array}{c}6 \mathrm{~A}, 8 \mathrm{~B}, 9,24 \\
10 \mathrm{~s}\end{array}$ & $\begin{array}{c}6 \mathrm{~A}, 8 \mathrm{~B}, 9,24 \\
10 \mathrm{~s}\end{array}$ & $9 / 46,46,44,45,47 / 12$ & $9 / 46,46,44,45,47 / 12$ \\
\hline & 3B. WCST 128 & Perseverations of criterion & $\begin{array}{c}6 \mathrm{~A}, 8 \mathrm{~B}, 9,24 \\
10 \mathrm{~s}\end{array}$ & $\begin{array}{c}6 \mathrm{~A}, 8 \mathrm{~B}, 9,24 \\
10 \mathrm{~s}\end{array}$ & $9 / 46,46,44,45,47 / 12$ & $9 / 46,46,44,45,47 / 12$ \\
\hline & 3C. WCST 128 & Perseverations of response & $\begin{array}{c}6 \mathrm{~A}, 8 \mathrm{~B}, 9,24 \\
10 \mathrm{~s}\end{array}$ & $\begin{array}{c}6 \mathrm{~A}, 8 \mathrm{~B}, 9,24 \\
10 \mathrm{~s}\end{array}$ & $9 / 46,46,44,45,47 / 12$ & $9 / 46,46,44,45,47 / 12$ \\
\hline & 3D. WCST 64A & Categories & $\begin{array}{c}\text { 6A, } 8 \mathrm{~B}, 9,24, \\
10 \mathrm{~s}, 10 \mathrm{i}, 11,25,32\end{array}$ & $\begin{array}{c}6 \mathrm{~A}, 8 \mathrm{~B}, 9,24, \\
10 \mathrm{~s}, 10 \mathrm{i}, 11,25,32\end{array}$ & $9 / 46,46,44,45,47 / 12$ & $9 / 46,46,44,45,47 / 12$ \\
\hline & 3E. WCST 64A & Perseverations of criterion & $\begin{array}{c}6 \mathrm{~A}, 8 \mathrm{~B}, 9,24 \\
10 \mathrm{~s}\end{array}$ & $\begin{array}{c}6 \mathrm{~A}, 8 \mathrm{~B}, 9,24 \\
10 \mathrm{~s}\end{array}$ & $9 / 46,46,44,45,47 / 12$ & $9 / 46,46,44,45,47 / 12$ \\
\hline & 3F. WCST 64A & Perseverations of response & $\begin{array}{c}6 \mathrm{~A}, 8 \mathrm{~B}, 9,24 \\
10 \mathrm{~s}\end{array}$ & $\begin{array}{c}6 \mathrm{~A}, 8 \mathrm{~B}, 9,24 \\
10 \mathrm{~s}\end{array}$ & $9 / 46,46,44,45,47 / 12$ & $9 / 46,46,44,45,47 / 12$ \\
\hline & 3G. WCST 64A & Set Loss & $10 \mathrm{i}, 11,25,32$ & $10 \mathrm{i}, 11,25,32$ & & \\
\hline & 3H. WCST 64B & Categories & $6 \mathrm{~A}, 8 \mathrm{~B}, 9,24,10 \mathrm{~s}$ & $6 \mathrm{~A}, 8 \mathrm{~B}, 9,24,10 \mathrm{~s}$ & $9 / 46,46,44,45,47 / 12$ & $9 / 46,46,44,45,47 / 12$ \\
\hline & 3I. WCST 64B & Perseverations of criterion & $\begin{array}{c}6 \mathrm{~A}, 8 \mathrm{~B}, 9,24 \\
10 \mathrm{~s}\end{array}$ & $\begin{array}{c}6 \mathrm{~A}, 8 \mathrm{~B}, 9,24 \\
10 \mathrm{~s}\end{array}$ & & \\
\hline & 3J. WCST 64B & Perseverations of response & $\begin{array}{c}6 \mathrm{~A}, 8 \mathrm{~B}, 9,24 \\
10 \mathrm{~s}\end{array}$ & $\begin{array}{c}6 \mathrm{~A}, 8 \mathrm{~B}, 9,24 \\
10 \mathrm{~s}\end{array}$ & $9 / 46,46,44,45,47 / 12$ & \\
\hline \multirow[t]{2}{*}{ 4. Stuss et al. (2001) } & 4A. Color naming & Color errors & & & & $\begin{array}{c}44,45 \mathrm{~A}, 45 \mathrm{~B}, 46 \\
9 / 46,8 \mathrm{~A}, 6 \mathrm{~A}, 6 \mathrm{~B}\end{array}$ \\
\hline & 4B. Stroop condition & Incongruent errors & $8 \mathrm{~B}, 9,32 \mathrm{~s}$ & $8 \mathrm{~B}, 9,32 \mathrm{~s}$ & & \\
\hline \multirow[t]{9}{*}{ 5. Stuss et al. (2002) } & 5A. Simple RT & Reaction time & $6 \mathrm{~A}, 8 \mathrm{~B}, 9,24$ & $6 \mathrm{~A}, 8 \mathrm{~B}, 9,24$ & & \\
\hline & 5B. Easy task & Simple-Easy difference & & & & $\begin{array}{c}44,45 \mathrm{~A}, 45, \\
47 / 12,11, \\
10,46,9 / 46,9,8 \mathrm{~B}, 8 \mathrm{~A}\end{array}$ \\
\hline & 5C. Easy task & Omissions & $6 \mathrm{~A}, 8 \mathrm{~B}, 9,24$ & $6 \mathrm{~A}, 8 \mathrm{~B}, 9,24$ & $\begin{array}{c}44,45 \mathrm{~A}, 45 \mathrm{~B}, 47 / 12,11 \\
10,46,9 / 46,9,8 \mathrm{~B}, 8 \mathrm{~A}\end{array}$ & \\
\hline & 5D. Complex task & Proportional increase & $\begin{array}{l}6 \mathrm{~A}, 8 \mathrm{~B}, 9,24 \\
10,11,25,32\end{array}$ & $\begin{array}{l}6 \mathrm{~A}, 8 \mathrm{~B}, 9,24 \\
10,11,25,32\end{array}$ & & $\begin{array}{c}44,45 \mathrm{~A}, 45, \\
47 / 12,11, \\
10,46,9 / 46,9,8 \mathrm{~B}, 8 \mathrm{~A}\end{array}$ \\
\hline & 5E. Complex task & Omissions & $6 \mathrm{~A}, 8 \mathrm{~B}, 9,24$ & $6 \mathrm{~A}, 8 \mathrm{~B}, 9,24$ & & \\
\hline & 5F. Complex task & False positives & & & $\begin{array}{c}44,45 \mathrm{~A}, 45,47 / 12,11 \\
10,46,9 / 46,9,8 \mathrm{~B}, 8 \mathrm{~A}\end{array}$ & \\
\hline & 5G. Redundant task & Proportion increase & $6 \mathrm{~A}, 8 \mathrm{~B}, 9,24$ & $6 \mathrm{~A}, 8 \mathrm{~B}, 9,24$ & & $\begin{array}{c}44,45 \mathrm{~A}, 45, \\
47 / 12,11, \\
10,46,9 / 46,9,8 \mathrm{~B}, 8 \mathrm{~A}\end{array}$ \\
\hline & 5H. Redundant task & Omissions & $6 \mathrm{~A}, 8 \mathrm{~B}, 9,24$ & $6 \mathrm{~A}, 8 \mathrm{~B}, 9,24$ & $\begin{array}{c}44,45 \mathrm{~A}, 45,47 / 12,11 \\
10,46,9 / 46,9,8 \mathrm{~B}, 8 \mathrm{~A}\end{array}$ & \\
\hline & 5I. Second simple task & Omissions & $6 \mathrm{~A}, 8 \mathrm{~B}, 9,24$ & $6 \mathrm{~A}, 8 \mathrm{~B}, 9,24$ & & \\
\hline \multirow[t]{2}{*}{ 6. Alexander et al. (2005) } & 6A.RT slowing. & & $9,24,32 \mathrm{~s}$ & 9 & $9 / 46$ & \\
\hline & 6B. Errors & & & & & $45 \mathrm{~A}, 45 \mathrm{~B}, 44,47 / 12$ \\
\hline \multirow[t]{3}{*}{ 7. Stuss et al. (2005) } & 7A. Choice RT & Reaction time & $9,24,32 \mathrm{~s}$ & & $9 / 46 v, 46$ & \\
\hline & $\begin{array}{l}\text { 7B. Prepare reaction } \\
\text { time }\end{array}$ & $\begin{array}{c}1^{\text {st }} \& 4^{\text {th }} \text { replications of } \\
\text { PRT, } 1 \text { sec warning }\end{array}$ & $9,24,32 \mathrm{~s}$ & & & \\
\hline & $\begin{array}{l}\text { 7C. Prepare reaction } \\
\text { time }\end{array}$ & $\begin{array}{c}2^{\text {nd }} \& 3^{\text {rd }} \text { replications of } \\
\text { PRT, } 3 \mathrm{sec} \text { warning }\end{array}$ & $9,24,32 \mathrm{~s}$ & & $\begin{array}{c}6 \mathrm{~A}, 9 / 46 \mathrm{~d}, 9 / 46 \mathrm{v}, 46 \\
45 \mathrm{~A}\end{array}$ & \\
\hline \multirow[t]{3}{*}{ 8. Picton et al. (2006) } & 8A. Go-no Go & Reaction time & $9,32 \mathrm{~s}, 24 \mathrm{~s}, 25$ & & & \\
\hline & 8B. Go-no Go & RT variability & $9,32 \mathrm{~s}, 24 \mathrm{~s}, 24 \mathrm{i}$ & & $44,45 \mathrm{~A}, 47 / 12$ & \\
\hline & 8C. Go-no Go & no-go false alarms & & $6 \mathrm{~A}, 8 \mathrm{~B}$ & & $6 \mathrm{~A}, 8 \mathrm{~B}$ \\
\hline 9. Floden \& Stuss (2006) & 9A. Stop signal task & RT slowing & $6 \mathrm{~A}, 8 \mathrm{~B}, 9$ & & & \\
\hline \multirow[t]{3}{*}{ 10. Picton et al (2006) } & $\begin{array}{l}\text { 10A. Tone paced } \\
\text { keeping time }\end{array}$ & $\begin{array}{l}\text { Variability to inter- } \\
\text { response interval }\end{array}$ & & & $44,45 B$ & \\
\hline & 10B. Self-paced & $\begin{array}{l}\text { Variability to inter- } \\
\text { response interval }\end{array}$ & & & $45 \mathrm{~A}, 8 \mathrm{Ad}$ & \\
\hline & $\begin{array}{l}\text { 10C. Accuracy \& } \\
\text { variability of timing }\end{array}$ & $\begin{array}{c}\text { Deterioration in } \\
\text { performance }\end{array}$ & $9,10 \mathrm{~s}, 32 \mathrm{~s}$ & $6 \mathrm{~A}, 8 \mathrm{~B}, 24 \mathrm{~s}, 32 \mathrm{~s}$ & $9 / 46 \mathrm{~d}, 10 \mathrm{~s}$ & $\begin{array}{l}9,8 \mathrm{~B}, 8 \mathrm{Ad} \\
9 / 46 \mathrm{~d}, 45 \mathrm{~B}\end{array}$ \\
\hline \multirow[t]{2}{*}{ 11. Alexander et al. (2007) } & $\begin{array}{l}\text { 11A. Modified Stroop } \\
\text { test }\end{array}$ & RT slowing & $6 \mathrm{~A}, 9,32 \mathrm{~s}, 24 \mathrm{~s}, 25$ & 9,25 & $8 \mathrm{Av}, 9 / 46 \mathrm{~d}, 9$ & \\
\hline & $\begin{array}{l}\text { 11B. Modified Stroop } \\
\text { test }\end{array}$ & False positives & & & & $9 / 46 \mathrm{v}, 47 / 12,45 \mathrm{~B}$ \\
\hline
\end{tabular}


Table 1. (Continued)

\begin{tabular}{|c|c|c|c|c|c|c|}
\hline Study & Condition & Variable & Right medial & Left medial & Right lateral & Left lateral \\
\hline \multirow[t]{2}{*}{ 12. Shallice et al. (2008) } & $\begin{array}{l}\text { 12A. Task-switching } \\
\text { single task }\end{array}$ & Number of errors & & & $6 \mathrm{~A}$ & $9 / 46 v$ \\
\hline & $\begin{array}{l}\text { 12B. Long Cue plus } \\
\text { Short Cue }\end{array}$ & Number of errors & & 9,14 & & \\
\hline \multirow[t]{2}{*}{ 13. Shallice et al. (2008) } & $\begin{array}{l}\text { 13A. Sustained } \\
\text { attention: Slow } \\
\text { condition }\end{array}$ & $\begin{array}{c}\text { Deterioration in } \\
\text { performance }\end{array}$ & $10 \mathrm{~s}, 9,32 \mathrm{~s}, 24 \mathrm{~s}$ & $9,24 \mathrm{~s}$ & $10 \mathrm{~s}$ & \\
\hline & 13B. Fast condition & $\begin{array}{c}\text { Deterioration in } \\
\text { performance }\end{array}$ & $9,32 \mathrm{~s}, 24 \mathrm{~s}$ & & $6 \mathrm{~A}, 8 \mathrm{Av}, 6 \mathrm{~B}, 44,45 \mathrm{~A}, 46$ & \\
\hline
\end{tabular}

Note. For each study we show the type of task and what was being measured, plus the localisation of impairment. The right-hand four columns specify more precisely the location of the lesions using Brodmann areas in respect of two brain surfaces (lateral, medial) and the two hemispheres (L and R). Typically, lesions encompassed more than one region in any one patient. In all conditions, the significance level was $p<0.05$; control groups vary. See Burgess, Gonen-Yaacovi and Volle, 2012, for full details of this meta-analysis. The reader will note that in the table we have tried to avoid using labels to describe the phenomena in relation to actual parts of the brain involved in a particular activity; we have rather described the task. This is an attempt to bring caution to the field. Many of the words that have been used in order to simplify our communications (e.g., inhibition, etc., even executive function) have not been shown to be psychometrically robust, or to discriminate well one task from another in behavioural terms. Moreover, simply ascribing roles to an area (e.g., orbitofrontal = reward processing; lateral PFC = working memory) may give the idea that more is known than actually is. The brain-behavior relationships indicated are more tethering points for further investigation, particularly from the viewpoint of network activity.

$\mathrm{V}=$ ventral; $\mathrm{d}=$ dorsal; $\mathrm{i}=$ inferior; $\mathrm{s}=$ superior; WCST $=$ Wisconsin Card Sorting Test.

demonstrating the complexity of network organization (Hwang, Bertolero, Liu, \& D’Esposito, 2017). It is likely this very significant reciprocal connectivity with so many different non-frontal regions not only resulted in the confusions in operational definitions but also provided the foundation for the prefrontal cortex's unique contribution to human functioning.

It seems likely at this point that researchers who study brain-behavior relations may move toward analysis at the level of brain circuits rather than isolated brain regions. This enterprise has already started (e.g., Thiebaut de Schotten et al., 2017). Moreover, Koechlin and colleagues (Koechlin, Ody, \& Kouneiher, 2003; Koechlin \& Summerfield, 2007; see also D'Esposito \& Badre, 2012) discussed an anteriorposterior hierarchy within the prefrontal cortex related to higher order processing requirements and selection of action.

\section{WHAT DO OUR TESTS MEASURE? ON THE PERILS OF MIXING LEVELS OF EXPLANATION}

How does one map construct onto brain circuit when one does not know which constructs one is measuring? For instance, prima facie the Category Test (CT) and the WCST are rather similar. In fact the CT and WCST probably share only around $30 \%$ common variance: "the CT and WCST should not be regarded as similar measures of one construct such as 'abstraction"' (Perrine, 1993, p. 461). The problem here perhaps is largely self-made. As mentioned above, the notion of "frontal lobe deficits" mixes levels of explanation (anatomy, information processing) in a dubious way. The tests measure various aspects of executive function, which may or may not be related to one or more regions of the frontal lobes.

This point was perhaps made most clearly by Alan Baddeley (e.g., Baddeley, 1986) as he introduced the term "dysexecutive" to refer to deficits in executive function. The big contribution here was to start to talk about what had previously been called "frontal lobe functions" in the same way that we talk about language or visuo-perceptual skills; we do not refer to these functional abilities by the regions of the brain (e.g., "temporal lobe function"). The inherent weakness of this theoretical innovation was, however, that the term "executive function" is an ill-defined collective for a range of abilities which may or may not relate to each other, and it invites endless re-invention. Nevertheless, it was probably a step in the right direction; let's call this new principle two:

New principle 2: Function and structure are two different levels of explanation; while a goal of neuroscience research is to understand these relationships, it is unrealistic to expect a simple correspondence in discourse between them.

\section{REASONS FOR WEAK PSYCHOMETRIC QUALITIES IN EXECUTIVE TASKS}

As noted above, it is not unusual to find low coefficients of reliability or internal consistency in executive tasks. Critical in this respect might be findings from both neuroimaging and other neuropsychological studies that relatively minor changes in task format can have marked effect upon results (e.g., Stuss et al., 2000; see also Table 1). Although this discovery is perhaps not entirely the product of the past 50 years of research into executive functions, this is probably nevertheless one that we might claim for this period with some justification.

New principle 3: Seemingly small changes in executive task format can lead to big differences in the results you get.

But why is it that small changes in format can make such a difference, and what does it mean for our understanding both of frontal lobe function and how to assess it? There are several possible explanations. One potential explanation for the apparent instability of many executive function tasks relates to changes in the novelty of the task. This may introduce individual differences into test variance that is hard to predict or control (Burgess, 1997). A second explanation is 
that individual variability within a test and consistency across tests and testing sessions are a necessary and lawful by-product of disturbed control processes (Stuss et al., 2003), that is, variability may itself be a dependent measurement. Third, there is the interface between emotion and cognition, which is often the role of the prefrontal region. Small changes in the phrasing of the task instructions emphasizing either the action that needed to be carried out, or the reward that would be won, led to differential patterns of activation within rostral prefrontal cortex (Gilbert, Gollwitzer, Cohen, Oettingen, \& Burgess, 2009; Figure 3). Fourth, differences in instructions are likely to call upon different processes to complete a task, seemingly independent of emotional/ cognition interplay (Floden, Vallesi, \& Stuss, 2011; Stuss et al., 2000).

Another potential, and perhaps related, explanation is that the frontal lobes are all about the self, and managing the self in terms of others. For instance Benoit, Gilbert, Volle, and Burgess (2010) used fMRI while two factors were crossed: (i) engaging in personality trait or episodic source memory judgments and (ii) the reference person for these judgments, which was either oneself or a friend. The imaging results suggested there may be complex aspects to do with social framing when administering executive tasks that we currently do not understand well, perhaps leading to inconsistencies in test-retest or inter-item statistics, and large variability between test participants.

New principle 4: Variability and inconsistency between and within patients are common. They should be measured and the possible reasons should be investigated during assessment.

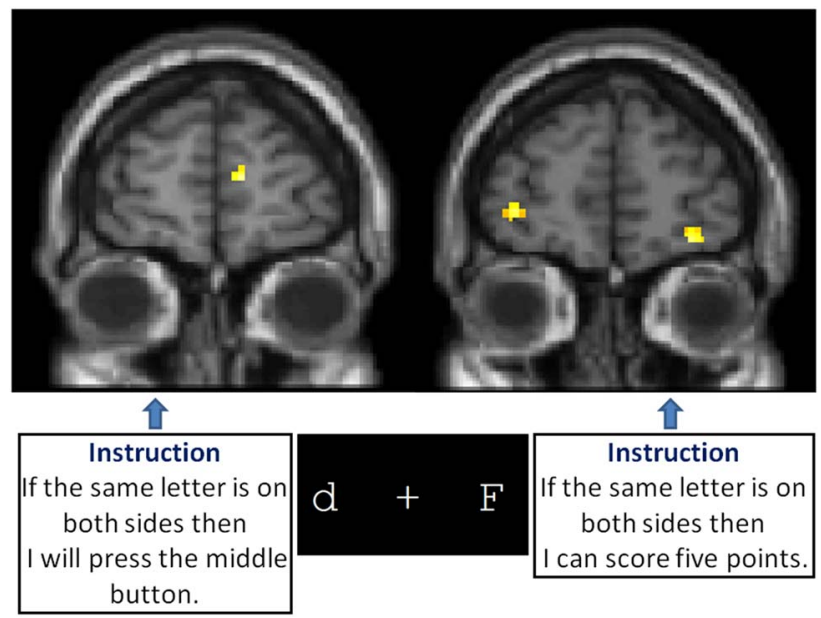

Fig. 3. Gilbert, Cohen, Gollwitzer, Oettingen, \& Burgess (2009) compared activation while participants were performing a computerized prospective memory task under two instruction conditions (shown in the text boxes in Figure 3). Nothing else about what the participants saw, heard or did was different. But the apparently minor changes in instruction were sufficient to change the patterns of activation seen in rostral prefrontal cortex (Brodmann Area 10), as well as change the performance of the participants (the instruction "If the same letter is on both sides then I will press the middle button" produced better performance).

\section{THERE IS NO "PREFRONTAL CORTEX SYNDROME": THE LIMITS OF ASSOCIATIONS AND DISSOCIATIONS.}

Demonstrations of failures of association between executive symptoms and/or executive test performances are probably more numerous than demonstrations of clear associations. Since there may be more reasons for null findings than significant ones, these findings were probably dismissed over the years, allowing the notion of the existence of a "frontal lobe syndrome" to perpetuate. But it has become clear over the past 50 years that the behavioral and cognitive symptoms of frontal lobe damage can show stark dissociations.

\section{Dissociations of Cognitive Symptoms of Frontal Lobe Damage}

One of the clearest early examples perhaps was that of Burgess and Shallice (1996b). Using the Hayling Sentence Completion Test (HSCT), they had three separate measures each using the same format of presentation, stimuli and response. Deficits in the three different measures could doubly dissociate from each other but were unlikely to be due to differences in task format or stimuli. Later, Volle et al. (2012) showed why this was the case: each of the three types of error was associated with lesions within different parts of PFC (see Figure 4).

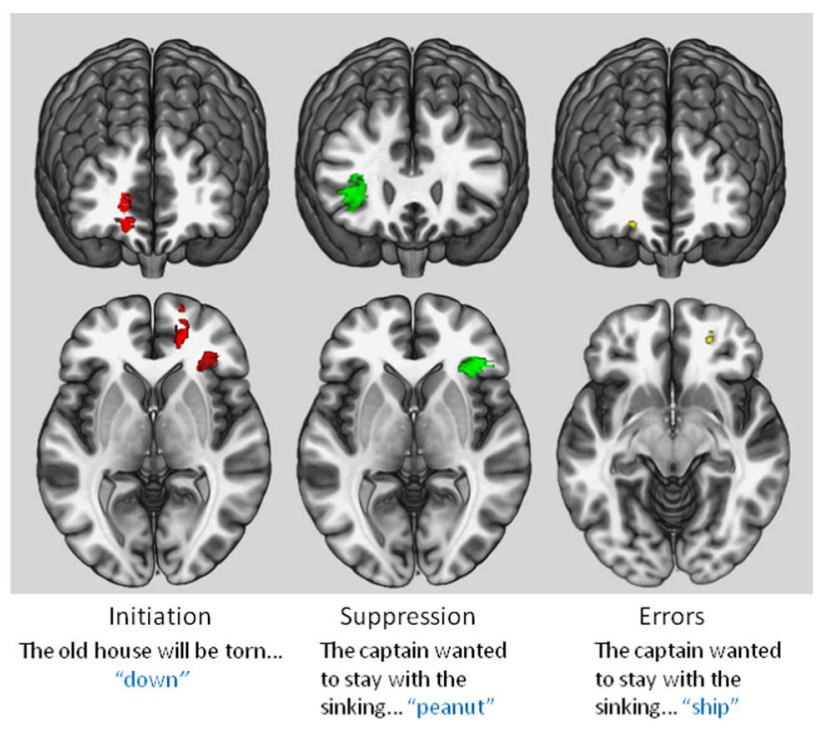

Fig. 4. Volle et al. (2012) used Burgess and Shallice's (1997) Hayling Sentence Completion Test to examine the neuroanatomical correlates of the three different types of failure on this task. In all conditions the participant is read a sentence that has the last word missing, and has to say a word in response. In the Initiation condition they are asked to produce a word that will complete the sentence as fast as they can. In the response suppression conditions, the participant is asked to produce a word that is unconnected the sentence. Volle found that lesions to the medial rostral prefrontal region caused initiation problems, while posterior inferolateral lesions caused, to different degrees, both initiation and suppression slowness, and an orbitoventral region was associated with errors in the suppression condition. (With thanks to Emmanuelle Volle for the brain pictures.) 
The (a) growth in demonstration of dissociations and (b) the sheer diversity of symptoms began the hunt for the limits of the "unity and diversity" of frontal lobe function (Teuber, 1972). It was perhaps inevitable, therefore, that the theoretical developments thenceforward might steadily get more complex. An example is the supervisory attentional system (SAS) account of Norman and Shallice (1986). It provided a good shorthand explanation for cardinal dysexecutive symptoms such as perseveration, problems with inhibition and dealing with novelty (e.g., the Cognitive Estimation Test). But the weakness of the original account is that it did not look inside the SAS "box" to unpack the structure of the system. Accordingly, the results from a series of lesion studies over the next 25 years were used to delineate the nature of the separate subsystems that putatively together comprise the SAS (Shallice \& Burgess, 1996; Shallice \& Cooper, 2011).

Other theorists were motivated more by the possibilities suggested by anatomical organization. For instance, Stuss and Benson (1986), guided by the work of Nauta, Pandya and others, emphasized the reciprocal interconnectivity of the frontal lobes with virtually all other brain regions to a degree far beyond other regions. As such, the frontal lobes appeared designed to have a major role in integrating and controlling information from all functional domains. They postulated four hierarchical levels of brain functional organization: (a) more posterior/basal fixed functional systems; (b) drive (medial frontal) and sequencing/setting/and integration (lateral frontal) functions; (c) anticipation, goal selection, pre-planning and monitoring as executive control functions (no localization proposed); (d) self-awareness and selfconsciousness (more anterior localization, and more integrated functioning), important for self-reflection, selfawareness, and awareness of one's self with society.

Stuss, Shallice, Alexander, and Picton (1995) approached the multiple processes theory combining the theoretical and anatomical approaches. The theoretical focus was on attention, as defined in the original theory of Norman and Shallice, but starting with the assumption that there are likely components of this attentional system. Closely allied with the first basic assumption is that a task measuring an attentional construct, such as sustained attention, is not equivalent to a fundamental process. An extensive literature review led to a grouping of tasks. All the tasks were analyzed, on the basis of which the authors postulated five frontal component processes related to the anterior attentional system and the interaction with more fixed posterior processes: energize a schema; inhibit a schema; adjust contention scheduling; monitor goal fulfilment, and if-then logic to adjust the system. Combinations of these processes were hypothetically able to explain performance on all of the different attentional tasks.

To test these ideas, a new battery of tests to investigate attention was developed: ROBBIA, the ROtman Baycrest Battery to Investigate Attention (see Stuss \& Alexander, 2007, for a summary of ROBBIA and sub-components). To isolate processes, the common assumption that the frontal lobes were needed primarily for novel and complex tasks was ignored, since complex or novel tasks would by definition require multiple integrated processes. The simplest single test was developed, which was then used as scaffolding upon which more complex demands were made. Well-known clinical tests, such as the Stroop, TMT, WCST, and Verbal Fluency were also included as an addendum to examine if similar processes could be revealed in both the clinical and experimental measures.

The results were consistent and replicated across different tests, different task modalities (i.e., memory, reaction time, language), and different patient groups (Alexander, Stuss, \& Fansabedian, 2003; Alexander, Stuss, Picton, Shallice, \& Gillingham, 2007; Alexander, Stuss, Shallice, Picton, \& Gillingham, 2005; Picton, Stuss, Shallice, Alexander, \& Gillingham, 2006; Picton et al., 2007; Shallice, Stuss, Alexander, Picton, \& Derkzen, 2008; Shallice, Stuss, Picton, Alexander, \& Gillingham, 2008; Stuss et al., 2005; Stuss, Binns, Murphy, \& Alexander, 2002; see Stuss \& Alexander, 2007, for an overview). No matter which task was used, including the clinical tasks (Stuss et al., 1998, 2001a, 2000; Stuss, Floden, Alexander, Levine, \& Katz, 2001b), task performance could be explained by three cognitively and anatomically distinct frontal processes. They were labeled: "energization," process of initiation or sustaining responses (clinically, think slowness, apathy); "task setting," ability to establish a stimulus-response relationship to respond to a target with specific attributes (clinically, think planning, organizing, learning how to do a new task); "monitoring," process of checking a task over time, and for quality control (clinically, think checking, staying on task).

Each was related to a different frontal brain region: energization, superior medial; task setting, left lateral; monitoring, right lateral. The term "executive" was reserved for the left and right lateral frontal functions. This was done because of the operational definition of the term executive as well as the influence of the dual origin of brain development (see below), and earlier experience with focal lesion patients such as in the leucotomy studies.

The results were a modification from the original hypothesized model. Energization and monitoring remained, but the hypothesized processes of if-then logic and adjusting contention scheduling seemed to be subsumed by the left lateral task setting/planning process. The focus on parsimony of processes through the development of scaffolded tasks also suggested that any of the supposed "inhibitory tasks," such as the Stroop, Suppression tasks, etc., all could be explained by one or more of the other processes such as energization or task setting (Alexander et al., 2007; Floden et al., 2011; Stuss \& Alexander, 2007; Stuss et al., 2001b).

These studies exemplify how the "newer" tests might be characterized psychometrically. The sub-group stratification results in less variance, and more consistent results. The major method is to illustrate that the same results can be demonstrated across different patient groups, across the same tests repeated, and across different modalities (i.e., the same processes with the same anatomical localization in attentional, language, and memory tasks). 
DISSOCIATIONS OF SOCIAL OR EMOTIONAL CHANGES AFTER FRONTAL LOBE DAMAGE?

Anatomy also suggested looking beyond attention to understand frontal lobe functions and emphasize that the terms dysexecutive and frontal lobe syndromes cannot be used interchangeably. Pandya and colleagues had reintroduced Sanides' concept of a dual origin of cerebral cortex development (Pandya \& Barnes, 1987; Pandya \& Yeterian, 1996). Two primordial regions, archicortical and paleocortical, representing hippocampal and olfactory areas, evolve, respectively, into a more dorsal system subserving sensory and cognitive processes, and a medial ventral/orbital system related to emotional functions. This representational division includes the frontal lobes, and suggests the importance of including emotional/behavioral regulation (paleocortical) in addition to attentional (archicortical) processes.

In the mid-1970s, Stuss and colleagues were provided the opportunity of studying the long-term effects of frontal leucotomies. Of particular fortune was that different groups of patients, all with similar diagnoses from the same institution by the same groups of physicians, could be compared on either having undergone or not a frontal leucotomy (seemingly the only long-term study with such a control) or on the degree of behavioral recovery after surgery.

Several important lessons were learned which paved the way for future research, as illustrated by the "good recovery" leucotomy patients. First, even though the patients were described as "frontal" patients, lesion location was an important factor. The leucotomy patients, with pathology primarily in orbitofrontal regions, were not significantly different from the matched normal control group on standard tests of "executive functions": WCST, TMT, Stroop, and several clinically used attentional measures such as Serial Sevens (Stuss et al., 1981, for overview). As was demonstrated by many labs later, these functions are subserved primarily by lateral frontal regions. There was a second corollary conclusion. If those tests are considered "executive," then not all regions of the prefrontal cortex should be considered as executive.

Third, to assess social behavior and emotional responsivity, the standard clinical personality tests were not valuable, and new tests had to be developed (Stuss \& Benson, 1983). In so doing, it was essential to dissociate the actual deficit underlying an impoverished score. In this instance, this demonstrated that the frontal leucotomy patients had full knowledge of appropriate social responsiveness, but did not apply this knowledge in a consistent manner. Fourth, the importance of context in assessment was emphasized.

Observationally, for example, the patients appeared to have a severe attentional disorder, but performed excellently in test situations. What was observed was the patient behaving in an unstructured situation; what was tested was their performance when the examiner "became the frontal lobes" of the patient in a regimented test situation. This led to the notion that it might be impossible to assess the executive function in an office setting for certain patients. However, it may be that it was the demands of the tests themselves that were the limiting factor, not the setting in which they were conducted (Burgess, Alderman, Volle, Benoit, \& Gilbert, 2009).

One of the advances of these early observations, therefore, was the demonstration of a potential separation between emotional and what been considered "cognitive" dysexecutive symptoms. A key study in this respect was the report of E.V.R. by Eslinger and Damasio (1985). The unfortunate man suffered bilateral ablation of orbital and ventromedial frontal cortices, and experienced "personality" and motivational changes that altered the course of his life. A critical aspect of this presentation was that his performance on IQ measures was still superior. Soon afterward, Shallice and Burgess (1991) also reported three cases who had suffered frontal lobe damage, in these cases, principally involving rostral PFC (area 10). All of these cases also had superior IQs, and did well on a range of neuropsychological tests.

However, like E.V.R., they had found it impossible to return to work. However, in their cases their deficits perhaps seemed slightly different in some respects from E.V.R.'s, seemingly most apparent in situations requiring multitasking and prospective memory. Deficits in these functions were then shown to be associated with damage to rostral (polar) damage in a group lesion study by Burgess et al. (2000), and a version of the Six Element multitasking test that was originally devised by Shallice and Burgess (1991) became part of the Behavioural Assessment of the Dysexecutive Syndrome (BADS) assessment battery.

Thus Shallice and Burgess pursued mainly the cognitive features of their patients' deficits. However, patient E.V.R. provoked a theory that dealt with the emotional aspects of patients' problems, called the somatic marker hypothesis (Damasio, 1996). This line of enquiry in turn led to the development of the Iowa Gambling Task (Bechara, Damasio, Tranel, \& Damasio, 2005), an attempt to create an objective neuropsychological measure of the emotional consequences of frontal lobe dysfunction. This spurred further initiatives in test development and interpretation of measures of social and emotional behavior (Clark, Cools, \& Robbins, 2004; Fellows \& Farah, 2005; Floden, Alexander, Kubu, Katz, \& Stuss, 2008; Sczcepanski \& Knight, 2014).

Starting from lobotomy studies and clinical cases, particularly E.V.R., evidence was consistent that damage to the orbitofrontal/ventral medial frontal regions resulted in a pattern of performance different from damage to the lateral frontal regions. These patients had notable emotional control and behavioral self-regulation problems, despite normal performance on the classic frontal lobes tests such as the WCST and the Stroop. A broader observation is that emotional and cognitive deficits after PFC damage could be dissociated from deficits in IQ and from each other with differences in anatomical localization. Newer concepts in network anatomical connectivity also supported the multiple frontal processes data.

Alexander, DeLong, and Strick (1986) reported five separate frontal cortical-subcortical circuits. Three of these circuits map onto the separate processes reported above, and 
Cummings (1995), although considering all as "executive," did differentiate them as drive, superior medial; emotional regulation, ventral medial; lateral-executive. Two of them, executive and emotional regulation, are consistent with the dual origin data. Finally, consistent with the original concept proposed by Stuss and Benson (1986) on self-awareness and self-consciousness, now supported by Pandya's description (personal communication) of the evolutionary importance of polar Brodmann area 10, research revealed a role of area 10 in metacognition and self-awareness (Craik et al., 1999; Shammi \& Stuss, 1999; Stuss, Gallup, \& Alexander, 2001; see also Wheeler, Stuss, \& Tulving, 1997).

Consideration of theory of mind and related process has been a useful segue for the field in considering social behavior changes in patients, and there have been related attempts looking at other aspects of social behavior (Channon, 2004).

Based on these anatomical and behavioral data, Stuss proposed there are four primary categories of frontal functions (Stuss, 2011a), each related to different brain regions: energization, task setting/planning, monitoring/checking, and metacognition. It is uncertain if more categories will be unveiled; however, it is highly likely that there are subdivisions within the categories, perhaps based on more precise localization or a hierarchical organization of representation, such as an abstract-concrete distinction (e.g., Badre, 2008). For example, there are different types of monitoring (Petrides, 2013); there appear to be hierarchies of "task setting" (D'Esposito \& Badre, 2012); and some of the functions of area 10 can be divided according to notions of stimulusoriented versus stimulus-independent attending.

More specifically, Burgess's "gateway hypothesis" (e.g., Burgess, Dumontheil, \& Gilbert, 2007) holds that one of the roles of rostral PFC (frontal lobe area 10) is to act as a control over attending either to stimulus-independent information (e.g., one's inner mental chatter) or to stimulus-oriented attending (e.g., attending to the outside world) with lateral and medial aspects of area 10 playing different roles within these attending modes (for review of the evidence see Burgess and $\mathrm{Wu}, 2013)$. So the emphasis here is on a mediallateral organization rather than a rostral-caudal one. Moreover, it appears that the medial PFC region that supports mentalizing is immediately caudal to the ones supporting this attentional gateway (Gilbert et al., 2006), so we assume this is a functionally different portion of PFC. Overall, whichever view is taken on these functional subdivisions, nowadays most theorists would feel comfortable arguing that the "executive" system consists of multiple interacting subsystems, perhaps not all deserving the label "executive." The question instead, is how many, and how do they interact with each other, and other systems within the brain.

New principle 5: What has been historically considered the executive system consists of multiple subsystems, with anatomical and behavioral separation. These separate systems will likely require several tests or measures to examine clinically.

Other accounts pursue the "unity" rather than the "diversity." Most notably, John Duncan and his colleagues in
Cambridge, United Kingdom, propose an account of frontal lobe function that relates to Charles Spearman's notions of " $g$ " or general intelligence (for review, see Duncan and Miller, 2013). On this "adaptive coding" account, PFC neurons do not have fixed functions. Instead, they have extensive and random inputs from a variety information sources, either from outside the individual (e.g., sensory or motor signals) or within it (e.g., memories and other stimulus-independent thoughts). As a result, there are large populations of neurons within PFC that can be involved in many apparently different functions, with the role that they play being determined by the behavioral context.

Duncan's elegant experiments have provided ample evidence to suggest that at least some subregions of PFC seem to support behavior across a wide range of situations rather than being specific to one (e.g., Duncan \& Owen, 2000). This wider application of functions is expressed as several domain general processes in the process specific model working together in more complex tasks (Stuss, 2011a). Another view of this more global influence type is that of the role of medial PFC in a "default mode network" (e.g., Raichle, 2015). From these works, we can propose that some parts of PFC seem to contribute to cognition that is used in many different situations.

New principle 6: Some executive processes are used in a wide variety of situations. So assessing them could be useful in predicting competence across a range of situations in everyday life.

\section{REPRESENTATIVENESS AS A POTENTIAL SOLUTION TO THE QUESTION "WHAT IS IT THAT THIS TEST MEASURES?”}

One expectation is that these levels of explanation (function, structure) will grow in ways that are related but independent from each other. This is already happening. For instance, prospective memory (the ability to carry out an intended action after a delay period filled with a distracting activity) is considered an executive function (although its origins were not in neuropsychology) but has grown into a mature research area which does not require reference to executive function for engagement, and also uses neuroimaging and experimental psychology techniques (see Burgess, GonenYaacovi, \& Volle, 2011; Gonen-Yaacovi \& Burgess, 2012, for review of neuroimaging and experimental psychology findings, respectively).

The move toward using neuropsychological tests that have greater "ecological validity" (or perhaps more correctly, representativeness) was substantially driven by this closely related clinical problem: if a patient fails a test of "frontal lobe dysfunction" what will it mean in terms of their disability in everyday life, or the treatment they should receive? Partly, this issue was addressed by the development of questionnaires aimed at characterizing the range of a patient's dysexecutive problems (e.g., the Dysexecutive Questionnaire (DEX) from the BADS (Wilson, Evans, Emslie, Alderman, \& Burgess, 1998); the Behavior Rating Inventory of 
Executive Function (BRIEF) (Gioia, Isquith, Guy, \& Kenworthy, 2000); the Frontal Systems Behavior Scale (FrSBe) (Grace \& Malloy, 2001), as well as screening measures such as the Frontal Assessment Battery (FAB) (Dubois, Slachevsky, Litvan, \& Pillon, 2000).

But another trajectory has been to develop psychometric tests more obviously related to performance in everyday life, such as the BADS battery Wilson et al, 1998), the various versions of Shallice and Burgess's (1991) Multiple Errands Test (e.g., Dawson et al., 2009; Knight, Alderman, \& Burgess, 2002) or naturalistic versions of the Six Element Test (e.g., Manly, Hawkins, Evans, Woldt, \& Robertson, 2002). The hope of this strand of test development is that by using tests that have greater representativeness (i.e., are more like "real-world" activities than say, the WCST), when a patient fails the test, it will be easier to predict what problems they would have in everyday life (Burgess, Alderman, Evans, Emslie, \& Wilson, 1998). A quite unexpected finding was that these tests often have psychometric properties that are comparable to, or better than, many experimentally derived experimental tasks (e.g., Dawson et al., 2009), even those invented within the past 50 years. A future experimental endeavor would be to relate distinct frontal lobe processes such as measured by ROBBIA to assist understanding of the mechanisms underlying failure on ecologically valid tests, a potential road to more precision targeted rehabilitation.

New principle 7: Tests that mimic naturalistic situations may be just as effective in terms of time-effectiveness, discrimination power, specificity, sensitivity, and ease of administration (and sometimes perhaps more so) as those that do not.

\section{IMPACT OF THEORY ON PRACTICE}

There are two basic guiding approaches to measuring executive deficits: (a) replicate the situation in testing where the person has a problem; (b) adopt a perspective based on a theoretical understanding of frontal lobe functioning. Most clinicians will adopt a mixture of the two of these, filtered through the availability of the psychometric tests available to them, and the appropriateness for that client group. This also impacts one's approach to rehabilitation. In terms of using theory as a guide, for instance, dysfunction in the single construct $g$ would be reflected in goal neglect (Duncan et al., 2008). Goal Management Therapy was designed to treat goal neglect (Levine et al., 2000). The multiple processes approach demands use of tests that are simple and focused, or can be deconstructed (i.e., the Boston process approach) (Stuss, 2007, 2011a, 2011b), so that the specific impairment might be revealed, and treatment directed to that specific impairment (e.g., self-awareness, task setting . . .), either in isolation or in sequence. Even when treating multiple processes, the approach would require awareness of the potentially differential impact of each process.

Understanding and treating the effects of traumatic brain injury has been viewed through this lens (Cicerone, Levin,
Malec, Stuss, \& Whyte, 2006; Stuss, 2011b). In research, if guided by a single construct theory, one might perhaps use more complex tests. A multiple process approach demands the construction of paradigms to measure separate processes, and the conditions that might affect the implementation of these processes. This approach is successful as well with fMRI studies (D'Esposito \& Badre, 2012; Floden et al., 2011; Vallesi, McIntosh, Alexander, \& Stuss, 2009; Vallesi, McIntosh, Crescentini \& Stuss, 2012; Vallesi, McIntosh, Shallice, \& Stuss, 2009).

The problem we face, however, is that in many cases the excellent theoretical advances that have been made in our understanding of the prefrontal cortex and the executive system over the past 50 years has not always been translated into new and better psychometric devices. Given the relatively primitive nature of the traditional tests we inherited they actually do a remarkable job in many situations. However, it has also become a principle of executive system assessment to say that whilst a deficit detected on an executive test might signify something noteworthy, the absence of such a finding does not mean that a deficit is not present. Very likely, this means that we just do not have the appropriate tools yet to detect that person's problems (see Burgess et al, 2009).

New principle 8: If your patient does not show a deficit on your executive tests, it does not mean that they don't have a problem. You just might not have tested the domain where their problem lies.

Our progress over the past 50 years is notable, but there is a long way to go. Partly this is because in the first couple of decades since the inception of functional neuroimaging, the streams of research and neuroimaging tended to develop quite independently. In some cases, this has probably led to errors in theorizing (see Burgess, Gonen-Yaacovi, \&Volle, 2012), and in many cases, paradigms that might have been usefully added to the neuropsychologist's arsenal have not made the leap from the brain scanning suite to the clinic. There are many new areas of cognition that are now being studied by neuroimaging techniques that are highly relevant for those of us who assess executive function (e.g., future thinking), and methodological cross-talk with related fields (e.g., developmental psychology/ psychiatry, e.g., Spitzer, White, Mandy, \& Burgess, 2016; Stuss, Gallup, and Alexander, 2001) is now fully under way and promises new perspectives and procedures.

Helfrich and Knight (2016) proposed the study of prefrontal cortex using oscillatory dynamics to understand its role in orchestrating networks. Furthermore, wireless functional near-infrared spectroscopy (fNIRS) has been used for the first time to measure activity in prefrontal cortex while people are carrying out executive activities (in this case, prospective memory) walking around a street environment (Pinti et al., 2015). The prospect of being able to gain realtime measurements of PFC activity while patients are engaged in the kinds of naturalistic tasks where they experience problems in everyday life opens up huge possibilities for cross-talk between neuroimaging and neuropsychology, bringing structure and function far closer together than is 
currently available. Thus we may be on the cusp of a new dawn for assessment of executive function.

\section{ACKNOWLEDGMENTS}

There are no conflicts of interest in relation to this manuscript. This study is a review of past literature, and there are no sources of financial support.

\section{REFERENCES}

Alexander, G.E., DeLong, M.R., \& Strick, P.I. (1986). Parallel organization of functionally segregated circuits linking basal ganglia and cortex. Annual Review of Neuroscience, 9, 357-381.

Alexander, M.P., Stuss, D.T., Picton, T., Shallice, T., \& Gillingham, S. (2007). Regional frontal injuries cause distinct impairments in cognitive control. Neurology, 68, 1515-1523.

Alexander, M.P., Stuss, D.T., \& Fansabedian, N. (2003). California verbal learning test: Performance by patients with focal frontal and non-frontal lesions. Brain, 126, 1493-1503.

Alexander, M.P., Stuss, D.T., Shallice, T., Picton, T.W., \& Gillingham, S. (2005). Impaired concentration due to frontal lobe damage from two distinct lesion sites. Neurology, 65, 572-579.

Anderson, C.V., Bigler, E.D., \& Blatter, D.D. (1995). Frontal lobe lesions, diffuse damage, and neuropsychological functioning in traumatic brain-injured patients. Journal of Clinical and Experimental Neuropsychology, 17(6), 900-908.

Baddeley, A.D. (1986). Working memory. Oxford: Clarendon Press.

Baddeley, A., Della Sala, S., Papagno, C., \& Spinnler, H. (1997). Dual-task performance in dysexecutive and nondysexecutive patients with a frontal lesion. Neuropsychology, 11, 187-194.

Badre, D. (2008). Cognitive control, hierarchy, and the rostrocaudal organization of the frontal lobes. Trends in Cognitive Sciences, 12, 193-200. doi: 10.1016/j.tics.2008.02.004

Bechara, A., Damasio, H., Tranel, D., \& Damasio, A.R. (2005). The Iowa Gambling Task and the somatic marker hypothesis: Some questions and answers. Trends in Cognitive Sciences, 9, 159-162.

Benoit, R.G., Gilbert, S.J., Volle, E., \& Burgess, P.W. (2010). When I think about me and simulate you: Medial rostral prefrontal cortex and self-referential processes. NeuroImage, 50, 1340-1349.

Benton, A.L. (1991). The prefrontal region: Its early history. In H.S. Levin, H.M. Eisenberg \& A.L. Benton (Eds.), Frontal lobe function and dysfunction (pp 3-34). New York: Oxford University Press.

Burgess, P.W. (1997). Theory and methodology in executive function research. In P. Rabbitt (Ed.), Methodology of frontal and executive function (pp 81-116). Hove, UK: Psychology Press.

Burgess, P.W., Alderman, N., Evans, J., Emslie, H., \& Wilson, B.A. (1998). The ecological validity of tests of executive function. Journal of the International Neuropsychological Society, 4, 547-558.

Burgess, P.W., Alderman, N., Volle, E., Benoit, R.G., \& Gilbert, S.J. (2009). Mesulam's frontal lobe mystery re-examined. Restorative Neurology and Neuroscience, 27, 493-506.

Burgess, P.W., Alderman, N., Forbes, C., Costello, A., Coates, L., Dawson, D.R., ... Channon, S. (2006). The case for the development and use of "ecologically valid" measures of executive function in experimental and clinical neuropsychology. Journal of the International Neuropsychological Society, 12, 1-16.
Burgess, P.W., Dumontheil, I., \& Gilbert, S.J. (2007). The gateway hypothesis of rostral prefrontal cortex (area 10) function. Trends in Cognitive Sciences, 11, 290-298.

Burgess, P.W., Gonen-Yaacovi, G., \& Volle, E. (2011). Functional neuroimaging studies of prospective memory: What have we learnt so far? Neuropsychologia, 49, 2246-2257.

Burgess, P.W., Gonen-Yaacovi, G., \& Volle, E. (2012). Rostral prefrontal cortex: What neuroimaging can learn from human neuropsychology. In B. Levine \& F.I.M. Craik (Eds.), Mind and the frontal lobes: Cognition, behavior, and brain imaging (pp. 47-92). New York: Oxford University Press.

Burgess, P.W., \& Shallice, T. (1996a). Bizarre responses, rule detection and frontal lobe lesions. Cortex, 32, 241-259.

Burgess, P.W., \& Shallice, T. (1996b). Response suppression, initiation and strategy use following frontal lobe lesions. Neuropsychologia, 34, 263-273.

Burgess, P.W., \& Shallice, T. (1997). The Hayling and Brixton tests. Bury St. Edmunds, UK: Thames Valley Test Company.

Burgess, P.W., Veitch, E., Costello, A., and Shallice, T. (2000). The cognitive and neuroanatomical correlates of multitasking. Neuropsychologia, 38, 848-863.

Burgess, P.W., \& Wu, H.-C. (2013). Rostral prefrontal cortex (Brodmann Area 10): Metacognition in the brain. In D.T. Stuss \& R.T. Knight (Eds.), Principles of frontal lobe function (2nd ed., pp. 524-544). New York: Oxford University Press.

Catani, C., Dell'Acqua, F., Bizzi, A., Forkel, S.J., Williams, S.C., Simmons, A., Murphy, D.G., \& Thiebaut de Schotten, M. (2012). Beyond cortical localization in clinico-anatomical correlation. Cortex, 48, 1262-1287.

Channon, S. (2004). Frontal lobe dysfunction and everyday problem-solving: Social and non-social contributions. Acta Psychologica, 115(2-3), 235-254.

Christensen, A.-L. (1975). Luria's neuropsychological investigation. New York: Spectrum Publications.

Cicerone, K., Levin, H., Malec, J., Stuss, D., \& Whyte, J. (2006). Cognitive rehabilitation interventions for executive function: Moving from bench to bedside in patients with traumatic brain injury. Journal of Cognitive Neuroscience, 18, 1212-1222.

Clark, 1, Cools, R., \& Robbins, T.W. (2004). The neuropsychology of ventral prefrontal cortex: Decision-making and reversal learning. Brain and Cognition, 55, 41-53.

Craik, F.I.M., Moroz, T.M., Moscovitch, M., Stuss, D.T., Winocur, G., Tulving, E., \& Kapur, S. (1999). In search of the self: A positron emission tomography study. Psychological Science, 10, 26-34.

Cummings, J.L. (1995). Anatomic and behavioral aspects of frontalsubcortical circuits. In J. Grafman, K.J. Holyoak \& F. Boller (Eds.), Structure and functions of the human prefrontal cortex, Vol. 769, pp. 1-13). New York: New York Academy of Sciences.

Damasio, A.R. (1996). The somatic marker hypothesis and the possible functions of the prefrontal cortex. Philosophical Transactions of the Royal Society of London B: Biological Sciences, 351, 1413-1420.

Dawson, D.R., Anderson, N.D., Burgess, P.W., Cooper, E., Krpan, K.M., \& Stuss, D.T. (2009). Further development of the multiple errands test: Standardized scoring, reliability, and ecological validity for the Baycrest version. Archives of Physical Medicine and Rehabilitation, 90(S1), 41-51.

Demakis, G.J. (2004). Frontal lobe damage and tests of executive processing: A meta-analysis of the category test, Stroop test, and trail-making test. Journal of Clinical and Experimental Neuropsychology, 26, 441-450. 
D'Esposito, M., \& Badre, D. (2012). Combining the insights derived from lesion and fMRI studies to understand the function of prefrontal cortex. In B. Levine \& F.I.M. Craik (Eds.), Mind and the frontal lobes. Cognition, behavior, and brain imaging (pp. 93-108). Oxford/New York: Oxford University Press.

Dubois, B., Slachevsky, A., Litvan, I., \& Pillon, B. (2000). The FAB: A frontal assessment battery at bedside. Neurology, 55, 1621-1626.

Duncan, J., \& Miller, E.K. (2013). Adaptive neural coding in frontal and parietal cortex. In D.T. Stuss \& R.T. Knight (Eds.), Principles of frontal lobe function (2nd ed., pp. 292-301). New York: Oxford University Press.

Duncan, J., \& Owen, A.M. (2000). Common regions of the human frontal lobe recruited by diverse cognitive demands. Trends in Neurosciences, 23, 475-483.

Duncan, J., Parr, A., Woolgar, A., Thompson, R., Bright, P., Cox, S., ... Nimmo-Smith, I. (2008). Goal neglect and Spearman's g: Competing parts of a complex task. Journal of Experimental Psychology: General, 137, 131-148.

Eslinger, P.J., \& Damasio, A.R. (1985). Severe disturbance of higher cognition after bilateral frontal lobe ablation. Neurology, 35(12), 1731-1741.

Fellows, L.K., \& Farah, M.J. (2005). Different underlying impairments in decision-making following ventromedial and dorsolateral frontal lobe damage in humans. Cerebral Cortex, 15, 58-63.

Floden, D., Alexander, M.P., Kubu, C., Katz, D., \& Stuss, D.T. (2008). Impulsivity and risk-taking behavior in focal frontal lobe lesions. Neuropsychologia, 46, 213-223.

Floden, D., Vallesi, A., \& Stuss, D.T. (2011). Task context and frontal lobe activation in the Stroop task. Journal of Cognitive Neuroscience, 23, 867-879.

Gilbert, S.J., Spengler, S., Simons, J.S.S., Steele, J.D., Lawrie, S.M., Frith, C.D., \& Burgess, P.W. (2006). Functional specialisation within rostral prefrontal cortex (area 10): A meta-analysis. Journal of Cognitive Neuroscience, 18(6), 932-948.

Gilbert, S.J., Gollwitzer, P.M., Cohen, A.L., Oettingen, G., \& Burgess, P.W. (2009). Separable brain systems supporting cued versus self-initiated realization of delayed intentions. Journal of Experimental Psychology: Learning, Memory, and Cognition, 35, 905-915.

Gilbert, S.J., Gonen-Yaacovi, G., Benoit, R.G., Volle, E., \& Burgess, P.W. (2010). Distinct functional connectivity associated with lateral versus medial rostral prefrontal cortex: A metaanalysis. NeuroImage, 53, 1359-1367.

Gioia, G.A., Isquith, P.K., Guy, S.C., \& Kenworthy, L. (2000). Behavior rating inventory of executive function. Child Neuropsychology, 6, 235-238. doi: 10.1076/chin.6.3.235.3152

Gonen-Yaacovi, G., \& Burgess, P.W. (2012). Prospective memory: The future for future intentions. Psychologica Belgica, 173(52/2-3), 173-204.

Grace, J., \& Malloy, P.F. (2001). Frontal Systems Behavior Scale (FrSBe). Lutz, FL: PAR.

Gratton, C., Nomura, E.M., Perez, F., \& D'Esposito, M. (2012). Focal brain lesions to critical locations cause widespread disruption of the modular organization of the brain. Journal of Cognitive Neuroscience, 24, 1276-1285.

Halstead, W.C. (1947). Brain and intelligence: A quantitative study of the frontal lobes. Chicago: University of Chicago Press.

Harlow, J.M. (1848). Passage of an iron bar through the head. Boston Medical and Surgical Journal, 39, 389-393.

Helfrich, R.F., \& Knight, R.T. (2016). Oscillatory dynamics of prefrontal cognitive control. Trends in Cognitive Science, 20, 916-930.
Hwang, K., Bertolero, M., Liu, W., \& D’Esposito, M. (2017). The human thalamus is an integrative hub for functional brain networks. Journal of Neuroscience, 37, 5594-5607.

Knight, C., Alderman, N., \& Burgess, P.W. (2002). Development of a simplified version of the multiple errands test for use in hospital settings. Neuropsychological Rehabilitation, 12, 231-255.

Koechlin, E., Ody, C., \& Kouneiher, F. (2003). The architecture of cognitive control in the human prefrontal cortex. Science, 302, 1181-1185.

Koechlin, E., \& Summerfield, C. (2007). An information theoretical approach to prefrontal executive function. Trends in Cognitive Science, 11, 229-235.

Levine, B., Robertson, I.H., Clare, L., Carter, G., Hong, J., Wilson, B.A., ... Stuss, D.T. (2000). Rehabilitation of executive functioning: An experimental-clinical validation of Goal Management Training. Journal of the International Neuropsychological Society, 6, 299-312.

Luria, A.R. (1966). Higher cortical functions in man (2nd ed.). New York: Basic Books.

Manly, T., Hawkins, K., Evans, J., Woldt, K., \& Robertson, I.H. (2002). Rehabilitation of executive function: Facilitation of effective goal management on complex tasks using periodic auditory alerts. Neuropsychologia, 40(3), 271-281.

Milner, B. (1963). Effects of different brain lesions on card sorting: The role of the frontal lobes. Archives of Neurology, 9, 90-100.

Norman, D.A., \& Shallice, T. (1986). Attention to action: Willed and automatic control of behavior. In R.J. Davidson, G.E. Schwartz \& D. Shapiro (Eds.), Consciousness and self-regulation: Advances in research. (Vol. IV, pp. 1-18). New York: Plenum Press.

Pandya, D.N., \& Barnes, C.L. (1987). Architecture and connections of the frontal lobe. In E. Perecman (Ed.), The frontal lobes revisited (pp. 41-72). New York: IRBN Press.

Pandya, D.N., \& Yeterian, E.H. (1996). Morphological correlations of human and monkey frontal lobes. In A.R. Damasio, H. Damasio \& Y. Christen (Eds.), Neurobiology of decision making (pp. 13-46). New York: Springer-Verlag.

Petrides, M. (2013). The mid-dorsolateral prefronto-parietal network and the epoptic process. In D.T. Stuss \& R.T. Knight (Eds.), Principles of frontal lobe function (2nd ed., pp. 79-89). New York: Oxford University Press.

Perrine, K. (1993). Differential aspects of conceptual processing in the Category Test and Wisconsin Card Sorting Test. Journal of Clinical and Experimental Neuropsychology Section A: Neuropsychology, Development, and Cognition, 15, 461-473.

Picton, T.W., Stuss, D.T., Alexander, M.P., Shallice, T., Binns, M.A., \& Gillingham, S. (2007). Effects of focal frontal lesions on response inhibition. Cerebral Cortex, 17, 826-838.

Picton, T.W., Stuss, D.T., Shallice, T., Alexander, M.P., \& Gillingham, S. (2006). Keeping time: Effects of focal frontal lesions. Neuropsychologia, 44, 1195-1209.

Pinti, P., Aichelburg, C., Lind, F., Power, C., Swingler, E., Merla, A., ... Tachtsidis, I. (2015). Using fibreless, wearable fNIRS to monitor brain activity in real-world cognitive tasks. Journal of Visualised Experiments, 106, e53336. doi: 10.3791/53336

Pribram, K.H. (1973). The primate frontal cortex-executive of the brain. In K.H. Pribram \& A.R. Luria (Eds.), Psychophysiology of the Frontal Lobes (pp. 293-314). New York: Academic Press.

Raichle, M.E. (2015). The brain's default mode network. Annual Review of Neuroscience, 38, 433-447. doi: 10.1146/annurevneuro-071013-014030

Reitan, R.M. (1958). Validity of the trail making test as an indicator of organic brain damage. Perceptual and Motor Skills, 8, 271-276. 
Reitan, R.M., \& Wolfson, D. (1995). Category test and trail making test as measures of frontal lobe functions. The Clinical Neuropsychologist, 9, 50-56.

Reverberi, C., Lavaroni, A., Giglib, G.L., \& Skrapb, M. (2005). Specific impairments of rule induction in different frontal lobe subgroups. Neuropsychologia, 43, 460-472.

Szczepanski, S.M., \& Knight, R.T. (2014). Insights into human behavior from lesions to the prefrontal cortex. Neuron, 83, 1002-1018.

Shallice, T. (1982). Specific impairments of planning. Philosophical Transactions of the Royal Society B: Biological Sciences, 298, 199-209.

Shallice, T., \& Burgess, P.W. (1991). Deficits in strategy application following frontal lobe damage in man. Brain, 114, 727-741.

Shallice, T., \& Burgess, P.W. (1996). The domain of supervisory processes and temporal organisation of behaviour. Philosophical Transactions of the Royal Society of London B, 351, 1405-1412.

Shallice, T., \& Cooper, R. (2011). The organisation of mind. Oxford, UK: Oxford University Press.

Shallice, T., \& Evans, M.E. (1978). The involvement of the frontal lobes in cognitive estimation. Cortex, 14, 294-303.

Shallice, T., Stuss, D.T., Alexander, M.P., Picton, T.W., \& Derkzen, D. (2008). The multiple dimensions of sustained attention. Cortex, 44, 794-805.

Shallice, T., Stuss, D.T., Picton, T.W., Alexander, M.P., \& Gillingham, S. (2008). Multiple effects of prefrontal lesions on task-switching. Frontiers in Human Neuroscience, 1, 1-12.

Shammi, P., \& Stuss, D.T. (1999). Humour appreciation: A role of the right frontal lobe. Brain, 122, 657-666.

Spitzer, D., White, S., Mandy, W., \& Burgess, P.W. (2016). Confabulation in children with autism. Cortex, 87, 80-95.

Stuss, D.T. (2007). New approaches to prefrontal lobe testing. In B. Miller \& J. Cummings (Eds.), The human frontal lobes: Functions and disorders (2nd ed., pp. 292-305). New York: Guilford Press.

Stuss, D.T. (2011a). Functions of the frontal lobes: Relation to executive functions. Journal of the International Neuropsychological Society, 17, 1-7.

Stuss, D.T. (2011b). Traumatic brain injury: Relation to executive dysfunction and the frontal lobes. Current Opinion in Neurology, 24, 584-589.

Stuss, D.T., \& Alexander, M.P. (2007). Is there a dysexecutive syndrome? Philosophical Transactions of the Royal Society of London. Series B: Biological Sciences, 362, 901-915.

Stuss, D.T., Alexander, M.P., Shallice, T., Picton, T.W., Binns, M.A., MacDonald, R., ... Katz, D.I. (2005). Multiple frontal systems controlling response speed. Neuropsychologia, 43, 396-417.

Stuss, D.T., Alexander, M.P., Hamer, L., Palumbo, C., Dempster, R., Binns, M., ... Izukawa, D. (1998). The effects of focal anterior and posterior brain lesions on verbal fluency. Journal of the International Neuropsychological Society, 4, 265-278.

Stuss, D.T., \& Benson, D.F. (1983). Emotional concomitants of psychosurgery. In K.M. Heilman \& P. Satz (Eds.), Advances in neuropsychology and behavioral neurology. Vol. 1. Neuropsychology of human emotion (pp. 111-140). New York/London: The Guilford Press.

Stuss, D.T., \& Benson, D.F. (1986). The frontal lobes. New York: Raven Press.

Stuss, D.T., Binns, M.A., Murphy, K.J., \& Alexander, M.P. (2002). Dissociations within the anterior attentional system: Effects of task complexity and irrelevant information on reaction time speed and accuracy. Neuropsychology, 16, 500-513.
Stuss, D.T., Bisschop, S.M., Alexander, M.P., Levine, B., Katz, D., \& Izukawa, D. (2001a). The Trail Making Test: A study in focal lesion patients. Psychological Assessment, 13, 230-239.

Stuss, D.T., Floden, D., Alexander, M.P., Levine, B., \& Katz, D. (2001b). Stroop performance in focal lesion patients: Dissociation of processes and frontal lobe lesion location. Neuropsychologia, 39, 771-786.

Stuss, D.T., Gallup, G.G., \& Alexander, M.P. (2001). The frontal lobes are necessary for "theory of mind". Brain, 124, 279-286.

Stuss, D.T., Levine, B., Alexander, M.P., Hong, J., Palumbo, C., Hamer, L., ... Izukawa, D. (2000). Wisconsin Card Sorting Test performance in patients with focal frontal and posterior brain damage: Effects of lesion location and test structure on separable cognitive processes. Neuropsychologia, 38, 388-402.

Stuss, D.T., Kaplan, E.F., Benson, D.F., Weir, W.S., Naeser, M.A., \& Levine, H.L. (1981). Long-term effects of prefrontal leucotomy- An overview of neuropsychologic residuals. Journal of Clinical Neuropsychology, 3, 13-32.

Stuss, D.T., \& Knight, R.T. (Eds.). (2002). Principles of frontal lobe function. New York: Oxford University Press.

Stuss, D.T., \& Knight, R.T. (Eds.). (2013). Principles of frontal lobe function (2nd ed). New York: Oxford University Press.

Stuss, D.T., Murphy, K.J., Binns, M.A., \& Alexander, M.P. (2003). Staying on the job: The frontal lobes control individual performance variability. Brain, 126, 2363-2380.

Stuss, D.T., Shallice, T., Alexander, M.P., \& Picton, T.W. (1995). A multidisciplinary approach to anterior attentional functions. Annals of the New York Academy of Sciences, 769, 191-212.

Teuber, H.L. (1972). Unity and diversity of frontal lobe functions. Acta Neurobiologiae Experimentalis (Wars), 32, 615-656.

Thiebaut de Schotten, M., Urbanski, M., Batrancourt, B., Levy, R., Dubois, B., Cerliani, L., \& Volle, E. (2017). Rostro-caudal architecture of the frontal lobes in humans. Cerebral Cortex, 27, 4033-4047.

Thurstone, L.L., \& Thurstone, T.G. (1938). Primary mental abilities. Chicago: University of Chicago Press.

Tilney, F. (1928). The brain, from ape to man. New York: Hoeber.

Vallesi, A., McIntosh, A.R., Alexander, M.P., \& Stuss, D.T. (2009). fMRI evidence of a functional network setting the criteria for withholding a response. NeuroImage, 45, 537-548.

Vallesi, A., McIntosh, A.R., Crescentini, C., \& Stuss, D.T. (2012). fMRI investigation of speed-accuracy strategy switching. Human Brain Mapping, 33, 1677-1688.

Vallesi, A., McIntosh, A.R., Shallice, T., \& Stuss, D.T. (2009). When time shapes behavior: fMRI evidence of brain correlates of temporal monitoring. Journal of Cognitive Neuroscience, 21, 1116-1126.

Volle, E., Costello, A., De L. Coates, L.M., Forbes, C., Towgood, K., Gilbert, S.J., ... Burgess, P.W. (2012). Dissociation between verbal response initiation and suppression after prefrontal lesions. Cerebral Cortex, 22, 2428-2440. doi: 10.1093/cercor/bhr322

Warrington, E.K. (2000). Homophone meaning generation: A new test of verbal switching for the detection of frontal lobe dysfunction. Journal of the International Neuropsychological Society, 6, 643-648.

Wheeler, M.A., Stuss, D.T., \& Tulving, E. (1997). Toward a theory of episodic memory: The frontal lobes and autonoetic consciousness. Psychological Bulletin, 121, 331-354.

Wilson, B.A., Evans, J.J., Emslie, H., Alderman, N., \& Burgess, P.W. (1998). The development of an ecologically valid test for assessing patients with a dysexecutive syndrome. Neuropsychological Rehabilitation, 8, 213-228. 